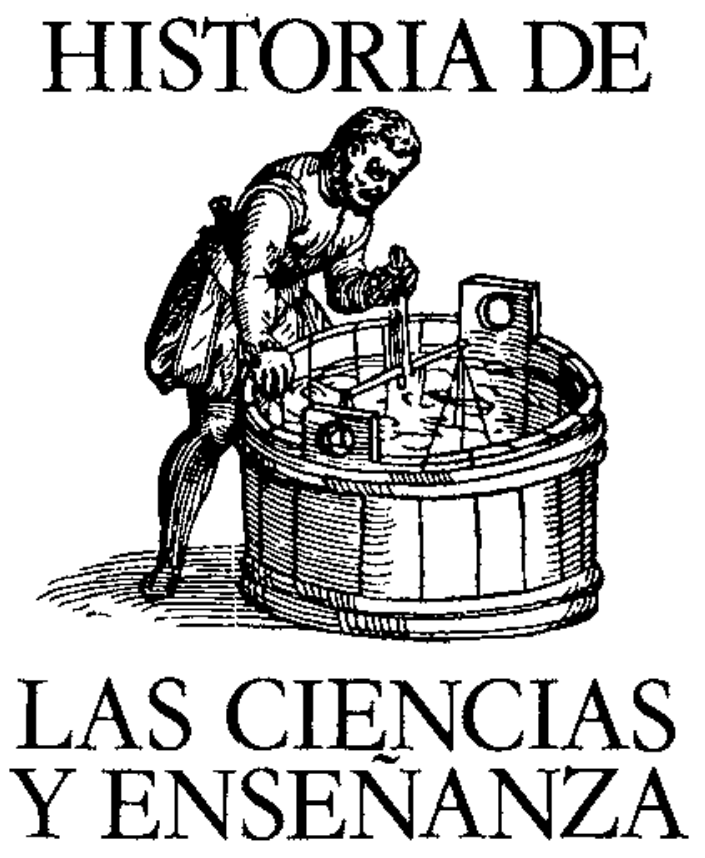

\title{
CONTRA EL MITO DE LA NEUTRALIDAD DE LA CIENCIA: EL PAPEL DE LA HISTORIA
}

\author{
CATALAN FERNANDEZ, A. y CATANY ESCANDELL, M. \\ Institut Ramón Lluli, Paima de Mallorca \\ Institut Verge de San Salvador, Felanitx
}

\begin{abstract}
SUMMARY
Most of the teachers of Science lack theoretical explicit elements to guide their educational action. So they contribute to transmit the myth of neutrality in the scientific orientation and development, and, in this case, Science can fulfil a ruling and justifying role. Against this proposal, we suggest a conscious assumption of some values in the general context of scientific education and even in the general one of a rational education. We put special emphasis on Science as a basic and necessary reference to individual and social behaviour, but not an exclusive one. We also propose: 1) recovering the utopic sense of Modern Science that took place in its origins, and 2) investiga* ting the environment, its past, present and future as a guide to place the student in a nonalienated from and selfforgetful connexion. And, finally, we declare for reason and against oppresion.
\end{abstract}

\section{LA TRANSMISION DE UNA VISION DE- FORMADA DE LA CIENCIA}

La mayoría de los ensehantes, y en concreto los de Ciencias (Naturales, Física, Química) solemos perder, o quizás no hemos adquirido, la conciencia de que nuestra parte en el proceso educativo se halla integrada, cua- 
litativa y cuantitativamente, en un todo más amplio. Olvidamos de este modo la influencia "del marco so. cial dominante en el que la escolarización tiene lugar, y que implica que los niños lograrán modos de pensamiento, normas sociales y principios de conducta, da. da su prolongada participación de ese marcon. (Dreeben, 1976).

Obviamos así el hecho de que el proceso educativo es un proceso unitario, intra y extraescolar, así como que no es posible diferenciar instrucción y educación, ya que, como settala Gramsci (1932), para que fuera posible lo primero sin lo segundo, "sería preciso que el alumno fuera mera pasividad, un mecanismo receptor de nociones abstractas'). Renunciando así a la explici. täión consciente de nuestro papel de educadores, y cediendo nuestro papel a otras personas y a otras disciplinas, las llamadas «humanidades», contribuimos a la transmision de una ciencia aparentemente «neutral». Perdidos en la marana de «ensentar saberes», olvidamos con frecuencia el "enseñar a saber» y siempre ei «enseñar a decidir», el "enseñar a actuar».

Cierto que la ciencia, como sistema de enunciados sobre la realidad es, según apunta Félix Von Cube (1983), axiológicamente neutra, pero, al margen de ello, casi nadie riega seriamente que la elección de los fines no procede de enunciados cientificos, sino que se trata, en cambio, de un problema filosófico, de un problema politico "para el cual ninguna ciencia puede darnos la solución». Más aún, y en esto no existe tanto acuerdo, creemos que el propio desarrollo metodológico de la ciencia, en contra del inductivismo de Bacon y seguidores, procede de esquemas formales ajenos a la pretendida "lógica de su desarrollo interno».

A las anteriores críticas, relativas a la supuesta auto nomía de la Ciencia, cabría añadir la referida al sobredimensionamiento creciente de la capacidad de la Cien. cia en la esfera de las decisiones individuales y colectivas. La Ciencia posee un sistema de valores, valores constitutivos (Aikenhead 1985), adecuado a un "mo" do» de conocimientos de una "realidad": el método experimental dirigido al conocimiento empírico de la realidad física. Pero ello no excluye la existencia en la ex* periencia humana de otros «modos» y «realidades». Es, por ello, erróneo y manipulador atribuir a la Ciencia la exclusiva de la valoración y la consecuente toma de decisiones en el campo de la moral, de la política, de la justicia...

Si limitamos la enseñanza de las Ciencias a una forma de diálogo con la realidad - cuando no, lo que sería más grave, a una simple relación de conocimientoscuya consecuencia sea la de su posible aplicación tecnológica o la del "saber por el saber», cometeremos, consciente $o$ inconscientemente, un fraude. Al trazar una divisoria infranqueable entre la ciencia y la política, ocultamos el hecho de su dependencia ideológica y de su utilización tecnocrática. La Ciencia no es neutral, como no lo son la metodologia docente y la selec- ción de contenidos que se transmiten. En la medida en que alimentamos el mito de la autonomia de la Ciencia la estaremos convirtiendo en producto utilizable por el mejor postor.

Esto resulta especialmente grave en un momento como el actual, en el que se tiende a sustituir la política por la discusión científica, lo que conduce al desarrollo de una conciencia tecnocrática. Dice Habermas (1968) que la peculiaridad de esta ideologia consiste en que «disocia la autocomprensión de la sociedad del sistema de referencia de la acción comunicativa y de los conceptos de interacción simbólicamente mediada y los sustituye por un modelo científicon. En sus propias pa. labras, esta conciencia tecnocrática "elimina las diferencias entre práctica y técnica». Por ello, hoy la Ciencia cumple funciones legitimadoras de dominio. En consecuencia, la enseñanza de las Ciencias, en el contexto de una educación liberadora, deberá desmitificar, desvelar ante los alumnos la intención subyacente a este modelo reduccionista.

Coherentemente con ello, proponemos que se ligue la enseñanza de las Ciencias con determinados valores, ya que renunciar a ello no significa que no se transmitan éstos. Se hace igual, pero involuntaria o implícitamente. Quienes rchuyen la conflictividad refugiándose en una pretendida "profesionalidad» de «enseñar Ciencia, simplemente» se convierten en agentes propagadores del nuevo valor absoluto que justificará, incontestablemente, lo que realmente son decisiones derivadas de los intereses de las clases y grupos dominantes. Son los sacerdotes propagadores de la justificación "cientifica» de un orden injusto, como otrora lo fueron la razón de la fuerza, de la estirpe o de la gracia de Dios.

Y bien, ¿qué valores deben ligarse a la enseñanza de las Ciencias?

Resultaría, desde luego, ingenuo reducir esta propuesta al ámbito de las Ciencias, ya que la enseñanza de éstas debe formar parte de un proceso de más alcance, que es la eđucación científica, y ésta, a su vez, de otro aún más amplio, que es la educación racional.

En esta perspectiva, la enseñanza de las Ciencias no podrá limitarse a un recitado de "conocimientos objetivos» ni tampoco al aprendizaje de un umétodo cientifico» presentado como fórmula mágica o receta magistral con la que incorporar la realidad al entendimiento, y de ahí a la acción. Resulta orientadora, a este respecto, la opinión de J.D. Bernal (1979) de que «las ideas científicas no son simplemente producto de la logica de los métodos experimentales; son, ante todo, ideas derivadas de la estructura social e intelectual de épocas anteriores, transformadas - y a menudo sólo parcialmente- al superar la prueba de la experimentación científicas.

Por ello, la educación científica, de la que forma parte la enseñanza de las Ciencias, deberá proponerse el 
desarrollo de una actitud critica, «irreverente» respecto a la realidad y sus interpretaciones. La educiación cientifica deberá proponerse lograr un individuo en el que el conocimiento científico sea básico, pero no la instancia única que oriente la acción moral y la acción política.

Del mismo modo que aceptamos que no puede existir una Ciencia sin conciencia, pues de ésta depende la medida humana de aquella, tampoco podemos aceptar una conciencia, una ética que no se base en la Ciencia, en lo que de conocimiento objetivo de la realidad ha podido obtener el hombre. Pero debe subrayarse que la ética no es la Ciencia, ni la Ciencia es neutral, (Aikenhead 1985).

La adquisición de una capacidad para decidir deberá inspirarse en un modelo en el que el hombre deje de ser prepotencia y dominación. En el que se abandone el suicida argumento de que debe hacerse todo lo que es posible hacer; en el que los datos, que nunca son inocentes, sean sólo un elemento más previo a la decisión. Un modelo, en suma, en el que se explicite que Las decisiones de los hombres y de los grupos provienen, en última instancia, de opciones que la demostración científica no puede demostrar ni refutar en su validez.

Tales referencias son, sin duda, ambiciosas, pero no negaremos que falta mucho por clarificar. Está casi todo por hacer $\mathrm{y}$, además, hay que nadar contra corritente. Fuera de nuestros confortables tratados de zoologia o bioquímica, de nuestros «sacrosantos programas revelados» (Giordan, 1978) todo es inseguridad y temor, porque, como indica Nietzsche, «inclinación, amor, placer, dolor, exaltación, creación, nada de eso conoce la ciencia. Lo que el hombre vive y experimenta, tiene él que interpretarlo para sí desde alguna parte; y de acuerdo con ello valorarlo»s.

\section{ENTRE LA HISTORIA Y EL FUTURO}

Es difícil, y quizá arriesgado, dar respuestas simples y seguras que orienten nuestra acción educativa. Existen, no obstante, algunas indicaciones sobre el camno que debería recorrer una ensextanza de las Ciencias que colaborase en la recuperación de un necesario sentido utópico.

Con excesiva facilidad en la ensentanza de las Ciencias se pierde de vista su historia. Podría decirse a este respecto que hemos perdido la memoria. Dar la espalda a lo que ha sido es una actitud peligrosa, también er. el caso de la Ciencia. Volver la vista y reflexionar sobre el origen y los cambios sufridos por la Ciencia nos permite ver que ésta nació al servicio de un proyecto utopico de revolución social. La Ciencia moderna nace como consecuencia de cambios de tipo económico, politico y social, a los que también contribuye.
Proponemos, por ello, recuperar los valores que le sub. yacían en el momento de su nacimiento y que han ido desnaturalizándose con el tiempo. Son los valores de la critica, la tolerancia, la participación, la cooperación, el diálogo. Y ello se puede lograr en un medio escolar en el que las relaciones del educando y la realidad y la historia no estén mediatizadas por el discurso dogmático del profesor. Aprender en la realidad, recuperar desde la experiencia colectiva el conocimiento de todo el difícil proceso histórico implicado en la generación de la Ciencia, investigando la trama económica, política y social que forma parte indistinguible del proceso científico; utilizar el medio ambiente como escenario físico resultante de unas relaciones de poder.

Este es el objetivo de la Educación Ambiental: llegar a alcanzar una relación no alienada con el medio. Es decir, cambiar la actual relación, basada fundamentalmente en la explotación y el consumo. Desde este punto de vista, en el medio, conjunto de elementos físicos, culturales, históricos, políticos, etc., se pueden distinguir tres momentos:

1. Pasado: el medio es, en este sentido, memoria, resultado de una historia que hay que recuperar.

2. Presente: el medio como conjunto de elementos que nos rodea y que genera conflictos que hay que resolver.

3. Futuro: el medio como sustrato, como materia preexistente, sobre la que hay que construir, cambiar, modificar.

Sólo de esta forma, por otra parte, se puede unir una cultura, una historia con un proyecto de futuro.

Las Ciencias y su enseñanza, incluidas dentro de cstas coordenadas cambian de carácter y de función:

1. El pasado o la historia de la Ciencia nos permite ver en qué momento nacio, qué factores influyeron o determinaron su nacimiento, qué valores le subyacian, etc.

2. El presente de la Ciencia y su relación con el pasado nos permite utilizarla para la resolución de problemas. Pero no se trata de problemas estrictamente «cientificos», sino problemas ambientales, con el objetivo de que el alumno tome conciencia de la complejidad inherente a la adopción de decisiones y de los innumerables factores que intervienen en ella (Aikenhead, 1985).

3. El futuro de la Ciencia aparece como la referencia que nos va a permitir configurar un medio, guiada por unos determinados valores.

Con todo, existe una gran incertidumbre sobre el desarrollo de una práctica docente en las coordenadas indicadas. Pero no es menos cierta la urgencia de una reflexion, de unas consideraciones intempestivas o molestas para quienes, embebidos en el «día a día» de la 
enseñanza olvidan -olvidamos - la necesidad de una idea básica que nos oriente. Una idea que seria, de acuerdo con Agnes Heller (1984), la del «partidismo en favor de la razon, unido a otro, al partidismo en favor de quienes más sufren, y actuar en el espiritu de estas dos obligaciones».

\section{REFERENCIAS BIBLIOGRAFICAS}

AIKENHEAD, G.S., 1985, Collective decision making in the social context of science. Science Education, 69 (4), 453-475. (Ver amplia reseña en Enseffanza de las Ciencias, 1986, 4 (1), 67-69).

BERNAL, J.D., 1979, Historia Social de la Ciencia (Península: Barcelona).

BETTI, G. 1976, Escuela, educación y pedagogia en Grams. ci (Martínez Roca: Barcelona).

CUBE, F.Yon, 1983, Educación en una sociedad abierta, Enrahonar, quaderns de Filosofia, 5/6, pp. 93-101.
DREEBEN, R., 1976, The unwritten curriculum and its relation to values. Curriculum Studies. V.8, pp. 11-124.

GIORDAN, A., 1982, La enseflanza de las ciencias, (Siglo XXI: Madrid).

HABERMAS, J., 1982, Sobre Nietzsche y otros ensayos. (Tecnos: Madrid).

HABERMAS, I., 1984, Ciencia y técnica como ideologia (Tecnos: Madrid).

HELLER, A., 1984, Critica de la llustración (Península: Barcelona). 